University of Nebraska - Lincoln

DigitalCommons@University of Nebraska - Lincoln

\title{
Estimating Nest Density When Detectability Is Incomplete: Variation In Nest Attendance And Response To Disturbance By Western Meadowlarks
}

\author{
Matthew D. Giovanni \\ University of Nebraska - Lincoln \\ Max Post van der Burg \\ University of Nebraska-Lincoln, maxpostvanderburg@usgs.gov \\ Lars C. Anderson \\ University of Nebraska-Lincoln, ars.c.anderson@gmail.com \\ Larkin A. Powell \\ University of Nebraska-Lincoln, Ipowell3@unl.edu \\ Walter H. Schacht \\ University of Nebraska - Lincoln, wschacht1@unl.edu \\ See next page for additional authors
}

Follow this and additional works at: https://digitalcommons.unl.edu/natrespapers

Part of the Natural Resources and Conservation Commons

Giovanni, Matthew D.; Post van der Burg, Max; Anderson, Lars C.; Powell, Larkin A.; Schacht, Walter H.; and Tyre, Andrew J., "Estimating Nest Density When Detectability Is Incomplete: Variation In Nest Attendance And Response To Disturbance By Western Meadowlarks" (2011). Papers in Natural Resources. 340.

https://digitalcommons.unl.edu/natrespapers/340

This Article is brought to you for free and open access by the Natural Resources, School of at DigitalCommons@University of Nebraska - Lincoln. It has been accepted for inclusion in Papers in Natural Resources by an authorized administrator of DigitalCommons@University of Nebraska - Lincoln. 


\section{Authors}

Matthew D. Giovanni, Max Post van der Burg, Lars C. Anderson, Larkin A. Powell, Walter H. Schacht, and Andrew J. Tyre 


\title{
ESTIMATING NEST DENSITY WHEN DETECTABILITY IS INCOMPLETE: VARIATION IN NEST ATTENDANCE AND RESPONSE TO DISTURBANCE BY WESTERN MEADOWLARKS
}

\author{
Matthew D. Giovanni ${ }^{1,2,3,4}$, Max Post van der Burg ${ }^{1,4,5}$, Lars C. Anderson ${ }^{1,2}$, Larkin A. Powell ${ }^{1}$, \\ WALter H. Schacht ${ }^{2}$, AND ANDrew J. Tyre ${ }^{1}$ \\ ${ }^{1}$ School of Natural Resources, University of Nebraska-Lincoln, Lincoln, NE 68583 \\ ${ }^{2}$ Department of Agronomy and Horticulture, University of Nebraska-Lincoln, Lincoln, NE 68583
}

\begin{abstract}
Researchers commonly model nest density as a function of ecological variables, but nests, like birds, can be undetected while present. In the Nebraska Sandhills in 2007, we used the rope-drag method on previously located Western Meadowlark (Sturnella neglecta) nests to model nest-detection error and nest density. Detecting nests by rope dragging (commonly used for nests of grassland birds) is conditional on two primary sources of nest availability, adults attending nests and adults flushing from nests in response to disturbance from the rope, the behavioral cue necessary for nest detection. On the basis of our trials with rope dragging, the probability of adults attending nests was 0.46 . The probability of trials eliciting flight responses from adults was 0.19 , indicating that observed estimates of nest density were subject to detection error and negatively biased. We compared our ability to detect differences in nest densities between two habitat types with a statistical power analysis, using (1) $t$-tests with estimates of apparent, uncorrected density and (2) a Bayesian hierarchical model incorporating nestdetection error. Our power analysis indicates that accounting for detection error in a hierarchical model increased statistical power for revealing differences in nest densities by habitat type. We discuss mechanisms underlying detection error for nests of grassland birds and make recommendations for sampling and modeling to maximize the reality of models for nest detectability and density.
\end{abstract}

Key words: Bayesian hierarchical model, detection error, false-negative errors, nest attendance, nest density, Sturnella neglecta, Western Meadowlark.

\section{Estimación de Densidad de Nidos cuando la Detectabilidad es Incompleta: Variaciones en las Visitas a los Nidos y Respuestas a Perturbaciones en Sturnella neglecta}

Resumen. La densidad de nidos es frecuentemente modelada en función de variables ecológicas, pero los nidos, como las aves, pueden no ser detectados aunque estén presentes. En Nebraska Sandhills en 2007, utilizamos el método de arrastre de cuerda en nidos previamente localizados de Sturnella neglecta para modelar el error asociado a la detección de nidos y la densidad de nidos. La detección de nidos con el método de arrastre de cuerda (usado frecuentemente para aves de pastizales) está condicionada por dos fuentes principales de disponibilidad de nidos, que los adultos estén visitando los nidos y que los adultos salgan del nido en respuesta al paso de la cuerda, lo cual es la señal comportamental necesaria para detectar los nidos. Con base en nuestras pruebas con este método, la probabilidad de que un adulto estuviera visitando el nido fue de 0.46 . La probabilidad de que el paso de la cuerda resultara en una respuesta por parte de los adultos fue de 0.19 , indicando que los estimados observados de densidad de nidos estaban sujetos a un error de detección y sesgados negativamente. Comparamos nuestra habilidad de detectar diferencias en las densidades de nidos entre dos tipos de hábitats con un análisis de poder estadístico, utilizando (1) pruebas de $t$ con estimados de densidad observada no corregida y (2) un modelo jerárquico Bayesiano que incorpora el error de detección de nidos. Nuestro análisis de poder indica que tener en cuenta el error de detección con un modelo jerárquico aumentó el poder estadístico para revelar las diferencias en las densidades de nidos por tipo de hábitat. Discutimos los mecanismos que subyacen al error de detección para nidos de aves de pastizal y brindamos recomendaciones para muestrear y modelar de modo de maximizar la realidad de los modelos que determinan la detectabilidad y la densidad de nidos.

Manuscript received 16 April 2010; accepted 7 October 2010.

${ }^{3}$ Current address: Canadian Wildlife Service, Prairie and Northern Region, Environment Canada, Regina, Saskatchewan S4P 4K1, Canada. E-mail: MatthewGiovanni@gmail.com

${ }^{4}$ Lead author.

${ }^{5}$ Current address: School of Forestry and Wildlife Sciences, Auburn University, Auburn, AL 36849.

The Condor, Vol. 113, Number 1, pages 223-232. ISSN 0010-5422, electronic ISSN 1938-5422. (C) 2011 by The Cooper Ornithological Society. All rights reserved. Please direct all requests for permission to photocopy or reproduce article content through the University of California Press's Rights and Permissions website, http://www.ucpressjournals.com/ reprintInfo.asp. DOI: 10.1525/cond.2011.100076 


\section{INTRODUCTION}

Researchers recognize the importance of accounting for individuals present but not detected in designs for sampling and modeling species occupancy (MacKenzie et al. 2002, Tyre et al. 2003), abundance or density (Royle 2004), and vital rates such as productivity (Powell et al. 1999) and nest survival (Shaffer 2004). While most research has focused on incomplete detectability of species, researchers also sample for indirect evidence of occupancy or abundance, such as nests, dens, hairs, scrapes, tracks, prey remains, and feces. Like the species that produce them, these products are also subject to detection error. Estimating density or abundance of items like nests, for example, with models that include a parameter for detection error is particularly important when ecologists are assessing effects of predictive ecological variables. Variation in detectability, which is inherently spatial and temporal, can bias the magnitude of covariates' estimated effects and accuracy of predictions. In the worst-case scenario, detection error can increase type 2 (false-negative) errors or, more rarely, type 1 (false-positive) errors, such that correlation with some ecological variable is inferred to be positive when it is negative or vice versa (Tyre et al. 2003).

We employ the definition of detectability as partitioned into two sources of error: availability and perceptibility (Johnson 2008). Availability represents systematic error associated with species-specific behavior that promotes or prevents detection, such as variation in singing by birds, breaching by whales, or burrowing by fossorial species. Perceptibility is conditional on availability and represents sampling error associated with the ability of observers to detect a target. Variation in observers' abilities (based on experience and aptitude) and environmental conditions (e.g., auditory or visual impediments like light, wind, rain, or topographic relief) are often primary sources of variation in perceptibility (Diefenbach et al. 2003, Alldredge et al. 2007, Simons et al. 2007). Given training and sufficient skill in sampling, an observer's ability to detect a target is determined by the availability of necessary cues that facilitate detection. Additional variation in detection error will arise if cues are used to detect targets but those cues are not uniformly available, as when rates of singing vary (Best 1981, Ralph 1981, McShea and Rappole 1997, Alldredge et al. 2007).

Some species, such as the Bald Eagle (Haliaeetus leucocephalus), build relatively conspicuous and detectable nests (Grier et al. 1981), while others, such as the Western Meadowlark (Sturnella neglecta), build cryptic ground nests (Davis and Lanyon 2008) that are more susceptible to falsenegative detection errors. The inconspicuousness of nests of the Western Meadowlark and other grassland birds generally requires nest-finding methods that are conditional on behavior of adults being observed (Winter et al. 2003). One common method is for two observers to drag a rope or chain between them to disturb and flush adults off nests (Bennett
1938, Labisky 1957, Higgins et al. 1969, Martin and Geupel 1993, Winter et al. 2003), the rope-drag method. This method is simple to use, but detecting $100 \%$ of nests present is conditional on (1) adults attending nests while the rope is dragged (a source of availability), (2) adults providing detection cues by responding to the rope (also availability), and (3) observers detecting flight responses by adults and then locating associated nests (perceptibility).

Birds attend nests at different rates within a day (Gloutney et al. 1993, Smith et al. 2009; Davis and Donald, in press) and through the nesting cycle (Powell et al., in press), which produces temporal variation in availability of nests for detection. Furthermore, breeding adults have disturbance- and stress-based response thresholds at which they choose their own safety over that of their offspring (e.g., Ricklefs 1977, Ydenberg and Dill 1986, Burhans and Thompson 2001, Ghalambor and Martin 2001). Additional variation in availability can therefore arise if the rope-drag method does not consistently achieve or surpass those response thresholds. Evidence thus indicates that the consistency of conditions required to avoid variation in nest availability and detection error is not achievable. Researchers could consequently survey areas by rope dragging, fail to detect some proportion of nests present, and then estimate negatively biased nest densities. Worse yet, researchers could survey areas by this method, fail to detect different proportions of nests among temporal and/or spatial factors of interest (e.g., habitat types or years), and then base statistical inference on biased estimates of nest density. Ultimately, modeling nest density as a function of ecological variables without accounting for detection error could lead to under- or over-estimating magnitudes or directions of ecological effects (Tyre et al. 2003).

Researchers commonly model nest density based on the rope-drag method as a response to or predictor of ecological variables, including crop type (Earl 1950, Cowan 1982, Duebbert and Kantrud 1987, Lokemoen and Beiser 1997, McMaster et al. 2005), haying or mowing (Frawley and Best 1991, Kershner and Bollinger 1996, Luscier and Thompson 2009; Devries and Armstrong, in press), livestock grazing (Bowen and Kruse 1993, Kruse and Bowen 1996, Fondell and Ball 2004), rates of nest depredation (Ackerman et al. 2004), prescribed burning (Kruse and Bowen 1996; Devries and Armstrong, in press), topography (Frey et al. 2008), climate (George et al. 1992, McLandress et al. 1996), habitat-patch size (O'Leary and Nyberg 2000, Arnold et al. 2007), and distance to habitat edge (O'Leary and Nyberg 2000, Renfrew et al. 2005). Relative nest densities among levels of ecological variables have been traditionally used as indices of true nest density, but indices are unbiased only if detection error is constant spatially, temporally, and among observers, which is most often not a realistic assumption (Best 1981, McShea and Rappole 1997, Diefenbach et al. 2003, Alldredge et al. 2007, Simons et al. 2007). 
Our objectives were to (1) model the probability of nest attendance by adult Western Meadowlarks, (2) model the probability of adults flushing from nests in response to rope dragging, (3) estimate detection-corrected nest densities for two habitat types with a Bayesian hierarchical model, and (4) conduct a statistical power analysis to compare the effectiveness of using observed versus detection-corrected estimates of nest density for revealing differences in nest densities between habitat types.

\section{METHODS}

\section{STUDY AREA AND SAMPLING}

Our study area was located at the University of NebraskaLincoln's Gudmundsen Sandhills Laboratory, which sits at the junction of Grant, Hooker, and Cherry counties $\left(42^{\circ} 4^{\prime} \mathrm{N}\right.$, $101^{\circ} 27^{\prime} \mathrm{W}$ ) in the central Nebraska Sandhills. The property includes approximately 5000 ha of upland prairie pastures and 500 ha of lowland wet meadow pastures and stream corridors. The Sandhills region is characterized by mostly linear sand dunes with topographic gradients in soil structure, water availability, and temperature, creating relatively xeric prairie plant communities (upland prairies) on the sand dunes and relatively mesic communities (wet meadows) a high water table within reach of plants' roots in the valleys. Wet meadows represent approximately $10 \%$ of the land area in the Sandhills and are typically managed for hay production, with a single annual harvest from early July to mid-August. Upland prairies are dominated by sparsely distributed warm-season grasses, forbs, and shrubs, whereas wet meadows support denser vegetation dominated by cool-season grasses, forbs, and sedges (Giovanni 2009). Upland prairies are generally managed with rotational or continuous grazing by beef cattle at moderate rates $\left(0.5-1.7\right.$ animal-unit months $\left.\mathrm{ha}^{-1}\right)$ from May through February, with a rest period in March and April. Thus topography and land management produced markedly different plant communities in wet meadows and upland prairies, collectively creating two distinct habitat types for Western Meadowlarks.

We focused our trials on nests of the Western Meadowlark because it is relatively abundant in the Sandhills and a widely distributed, grassland-obligate species (Davis and Lanyon 2008). We located nests by rope dragging and by fortuitous encounters in wet meadow and upland prairie pastures from 22 May to 30 July 2007. We searched each pasture two to four times by rope dragging and used a geographic-information system to estimate area searched per pasture. We used modified visual-obstruction poles (Robel et al. 1970) to estimate vegetation density around nest bowls within 1 to 3 days of a nest's abandonment. We conducted trials by having two primary observers drag a weighted $27-\mathrm{m}$ rope once over previously located nests from a random direction approximately $50 \mathrm{~m}$ away from each nest. Trials concluded when (1) a nest-attending adult flushed in response, or (2) an adult did not flush and we subsequently approached and visually inspected the nest for presence or absence of the adult. We excluded the trial from the analysis if the nest attempt had been terminated. While there is some uncertainty regarding detection of adults that could have run from the nest, we never observed this occurrence, and no data to support the occurrence of such behavior exist. We therefore assumed that our ability to detect responses by adults was constant because (1) there was no evidence suggesting that adults run from the nest, (2) the same two observers intently focused on nest sites during trials, and (3) our many observations through three breeding seasons of searching for nests by rope dragging indicate that an adult flushing from a nest is audibly and visually conspicuous.

We assumed nest detectability did not vary across the sampling period because Powell et al. (in press) identified nest stage (egg versus nestling) as the primary source of variation in the probability of a Western Meadowlark attending a nest at the same study sites. We had no biological reason to expect rates of nest attendance and consequent nest detectability to vary through the breeding season because Western Meadowlarks commonly renest multiple times within one breeding season (Davis and Lanyon 2008), thereby ensuring that nests in both stages were available for trials throughout the breeding season. To assess this assumption with our data, however, we also included an ordinal-day model in our set of competing models for estimating probabilities of nest attendance and flushing by adults.

We allowed a minimum of two days to pass before repeating trials at nests that survived for longer periods, and we assumed trials to be independent with respect to behavioral responses from adults (i.e., there was no "rope-happy" or "rope-shy" behavior based on previous trials). We attempted to conduct trials at least once during both egg and nestling stages because rates of nest attendance vary by stage (Smith et al. 2009; Powell et al., in press). Some nests, however, failed during the egg stage, and others were found during the nestling stage, thereby preventing trials at both stages for all nests. We also attempted to distribute trials evenly through the day because of potential intra-day variation in nest-attendance rates (Gloutney et al. 1993; Davis and Donald, in press).

\section{STATISTICAL ANALYSES}

We used R version 2.6 (R Development Core Team 2007) for statistical modeling. We developed a set of competing a priori generalized linear models with logit-link functions (Bolker 2008) to estimate probabilities of adults attending nests and flushing from nests in response to rope-drag trials. Models included (1) a null model, (2) a time-of-day model, (3) an ordinal-day (season) model, (4) a nest stage (egg or nestling) model, (5) a model for density of vegetation around the nest site, and (6) a global model. We used Mazerolle's (2010) "AICcmodavg" package version 1.13 to calculate parameters for 
selection of models, assess model support, and model-average coefficients for multimodel inference (Anderson 2008).

Flushing by adults in response to trials may have varied in part because of previous rope-drag trials, akin to "trap-shy" or "trap-happy" behavior, potentially creating non-independence among responses to trials. We therefore assumed that prior exposure to a trial did not influence the probability of an adult's response to subsequent trials. We assessed our assumption of independence between trials by modeling comparative probabilities of adults flushing at nests that were and were not exposed to prior trials. Variation in adults' flushing responses may have also been affected by the fact that our trials were biased toward nests that survived longer, whereas nests that failed at relatively early ages were less likely to be represented in our sample (sensu Mayfield 1961). Therefore, although we attempted to distribute trials across nest stages (ages), the possibility exists that adults at nests that failed early could have responded to trials at rates different from those of adults at nests that survived longer. For example, adults at nests that tend to succeed may be less likely to flush in response to presence of predators, potentially concealing nest locations at higher rates. Alternatively, they may be more likely to detect predators and flush before predators detect nests. For our analysis, we assumed that the responses of adults at failed and successful nests did not vary. We assessed this assumption by modeling and comparing probabilities of flushing by adults at nests that did and did not survive long enough to (1) transition from the egg stage to nestling stage and (2) successfully fledge nestlings.

We used two simulation models and a power analysis to quantify the effect of nest-detection error on our ability to reveal differences in nest densities between two habitat types. The first simulation model compared apparent mean estimates of nest density in the two habitat types with results of iterative, one-tailed $t$-tests $(\alpha=0.05)$ and represented the more traditional approach of analysis. The second simulation model predicted corrected nest densities by accounting for detection error with a Bayesian hierarchical model. We parameterized the simulation models on the basis of the field-sampling design used to find nests for a related study of nest survival and selection (Giovanni 2009), where seven sites were classified as lowland wet meadows and four sites were classified as upland prairies.

Our first model simulated pastures that were visited from one to four times in a search for new nests. We simulated data by assuming the number of new nests found during each visit arose from a Poisson process. We made this assumption because finding a nest is a discrete event and, from an observer's perspective, an independent random event that occurs at a particular rate. Thus, during each simulated visit, new nests were "found" as random draws from a Poisson process (Pois):

$$
N_{i j} \sim \operatorname{Pois}\left(\lambda_{c} A_{i}\right)
$$

where $N$ is the number of new nests in the $i$ th pasture on the $j$ th visit, $\lambda$ was the average nest density for one of the habitat types $c$, and $A$ was the area in hectares of the $i$ th pasture. These definitions of indices and parameters remain the same throughout the rest of the description of the model. By estimating $\lambda$ in this way, we made inferences about the number of nests an observer was expected to find given a search of a specified area of size $A$. We simulated variation in sampling effort (i.e., number of visits to a pasture) as a random draw from a uniform distribution with a range of 1 to 4, which represents the variation in our field-sampling effort because sample size increases with effort. We assumed that the mean rate of nest detection was constant across visits in our simulations, although one could model the mean rate as a function of time if evidence indicated that the mean declined over the course of the breeding season or with consecutive visits.

We introduced detection error into simulated nest discoveries during each visit with the following binomial process (Bin) because finding a nest is a discrete event:

$$
y_{i j} \sim \operatorname{Bin}\left(N_{i j,} p\right)
$$

where $y$ is the apparent number of nests and $p$ is the detection rate. We assumed that only a portion $p$ of the Poisson-distributed $N$ nests was found at any one time. Thus, we treated the number of nests found as a random draw from a binomial realization of the Poisson process. Simulating our data thus consisted of making random draws from a Poisson distribution, inserting the resulting values into a binomial distribution, and then making random draws from a binomial distribution. We used our field-based empirical estimate of overall probability of flushing for $p$ in the binomial distribution. We calculated simulated apparent densities of nests for each habitat type by summing simulated numbers of observed nests $(y)$ in each pasture over all visits and then dividing by pasture area. We then tested for differences in simulated nest densities by habitat type with independent, one-tailed $t$-tests $(\alpha=0.05)$.

We began this simulation under a scenario where habitat types had equal mean nest densities of 0.1 nests $^{-1} \mathrm{a}^{-1}$, the estimated nest density from our observed data for the uplandprairie habitat type. We then increased mean nest density in the wet meadows by 0.005 nests ha ${ }^{-1}$ because we felt this value was precise enough for us to accurately identify thresholds in statistical power. We increased densities in wet meadows to find a threshold for power with regard to our expected effect of habitat type. We repeated nest-density increases for wet meadows until the difference in mean nest density between habitat types reached 0.30 nests ha $^{-1}$, a difference large enough to illustrate the effect of detection error on power. For each increase in nest density, we simulated 1000 datasets, which consisted of observations of nests in each of the 11 pastures. We recorded the proportion of datasets in which the $t$-test identified a significant difference in mean nest densities between habitat types. 
We then developed a second simulation that used a Bayesian hierarchical model (McCarthy 2007) to correct for detection error and predict nest densities. As in the previous analysis, we simulated an apparent number of nests $(y)$ on the basis of a binomial distribution with the empirical detection probability $p$. The true number of nests $(N)$ was based on a Poisson distribution. As in the first analysis, we calculated the simulated apparent nest density from the observed number of nests $(y)$ in each pasture and the area of each pasture. We then analyzed the simulated data by fitting the following mixture likelihood based on Royle's (2004) $N$-mixture model:

$$
\prod_{j=1}^{J} \prod_{j=1}^{I} \operatorname{Bin}\left(y_{i j} \mid N_{i j,} p\right) \operatorname{Pois}\left(N_{i j} \mid \lambda_{i}\right)
$$

where $p$ was estimated by logistic regression and $\lambda$ was estimated by Poisson regression. This method of analysis is different from the $t$-test used in the first analysis because it corrects average estimates of nest density for detection error by assuming that the true number of nests $(N)$ was not directly observed but could be estimated as a parameter. We estimated mean densities for each pasture as the mean of an overdispersed Poisson model:

$$
\log \left(\lambda_{i}\right)=\mu A_{i}+\varepsilon_{i}
$$

where $\mu$ is a collection of log-linear model parameters $\left(\beta_{0}+\beta_{1} \times\right.$ habitat type) and $\varepsilon$ is a random effect for each pasture with a zero mean and a variance to be estimated. We included this error term to account for additional statistical errors at the level of the pasture that could not be accounted for by the mean. We parameterized the variance term as the inverse variance ( $\tau$, Bayesian precision), which is common in Bayesian analyses because of how posterior conditional distributions are derived. The covariate for the habitat-type parameter in our Poisson regression was a binary variable ( 1 = wet meadow, $0=$ upland prairie).

We fit our hierarchical model by Markov chain Monte Carlo (MCMC) simulation with a metropolized Gibbs sampler (Gilks et al. 1995, Robert and Casella 1999), similar to methods used in the software package WinBUGS (Lunn et al. 2000). Our algorithm used a Gibbs sampler or Metropolis algorithm depending on the availability of the full conditional distribution (i.e., the distribution of a parameter given all of the other quantities in the model). Sometimes we were able to build conditional distributions that were proportional to the product of the prior of the parameter and the likelihood of that parameter. The resulting distribution function was then easy to use because we sampled directly from it, which is known as Gibbs sampling. In other cases, we could not derive this function because we could not easily multiply the prior times the likelihood, such as with the mixture model presented above. Instead we developed an approximating function and iteratively proposed new values that could belong to that distribution, which is known as the Metropolis algorithm. The steps of our hybrid algorithm are as follows:

(1) We drew new values of $p$ for each pasture during each visit from a normal distribution with mean of logit(0.19) and standard deviation of 0.05 . We estimated the parameters of this distribution from our empirical data.

(2) We updated values of the pasture-specific mean nest density $(\lambda)$ by using a Metropolis updating step, which estimates a parameter by evaluating the relative probability between the current value and newly proposed values of the parameter. This relative probability $r$ is represented as:

$$
r_{i}=\frac{\operatorname{pr}\left(\lambda_{i} * \mid N_{i j, p}\right)}{\operatorname{pr}\left(\lambda_{i} \mid N_{i j,} p\right)}
$$

where $\lambda_{i}$ is the current value and $\lambda_{i}^{*}$ is the new value proposed as a random draw from a normal proposal distribution with mean $\lambda_{i}$ and standard deviation 0.10 . We then drew the probability of accepting the new nest-density value from a uniform distribution on the interval $[0,1]$. If $r$ was less than the random acceptance probability then we kept the old value. If $r$ was greater than the acceptance probability, we accepted the new value. We used this method for all of the parameters for which we could not compute the full conditional distribution.

(3) We updated the "true" number of nests by randomly increasing or decreasing the current value of each $N$ by 1 . Proposed values of $N$ had no upper limit, but they could not go lower than the observed value of $y$. We then accepted or rejected these new values according to a Metropolis step:

$$
r_{i j}=\frac{\operatorname{pr}\left(N_{i j} * \mid \lambda_{i, p}\right)}{\operatorname{pr}\left(N_{i j} \mid \lambda_{i, p}\right)}
$$

Again, we accepted or rejected each value of $N_{i j}$ (the true number of nests in the $i$ th pasture on the $j$ th visit) by comparing $r_{i j}$ against an acceptance probability.

(4) We updated the values of $\mu$ ( $\beta_{0}$, etc.) by using a Gibbs sampler, which works by drawing values from the full conditional distribution. In our case, this was represented as a multivariate normal distribution (MVN):

$$
\mu \sim \operatorname{MVN}(\bar{\mu}, 1 / \tau n)
$$

where $\bar{\mu}$ is a vector means for the log-linear model and $n$ is the number of pastures.

(5) We updated the current value of our precision, $\tau$, by drawing values from a full conditional gamma distribution:

$$
\tau \sim \operatorname{Gamma}\left\{1 / 10,1 / 10+0.5\left[\sum\left(m_{i}-\mu\right)^{2}\right]\right\} .
$$

We assumed an inverse-gamma prior with a mean of 1 and variance of 10 . This produced a relatively uninformative prior distribution with a strong peak around a value of 1 and a $95 \% \mathrm{CI}$ 
that covers values close to zero $(1 / \tau$ is very large) up to values around $10(1 / \tau$ is small $)$.

Algorithms sometimes have difficulty converging on an estimate when the Markov chain generated in these simulations is based on a complicated likelihood, and a common solution is to run the chain from a long number of iterations (i.e., use a burn-in period) to allow the chain to settle into a stationary sampling distribution (Gilks et al. 1995, McCarthy 2007). We ran our algorithm for a single chain with 110000 iterations, and discarded the first 10000 iterations. We used the last 100000 as our stationary distribution and thinned each chain to every 100 iterations in order to reduce the amount of serial autocorrelation, which can affect estimates of the posterior variance of a parameter (Gilks et al. 1995). Thus our posterior inference was based on 1000 iterations. We simulated 100 replicate datasets for each change in nest density in wet meadows. We ran fewer datasets for the Bayesian model because of the time-consuming process of fitting the model. For instance, in some cases it took $\geq 3 \mathrm{hr}$ to finish 100 replicates for one mean value. In order to speed up the processing, we used a parallel processing approach with Prairiefire, a bank of $400+$ processors maintained at the University of NebraskaLincoln's Research Computing Facility.

Once parameters were estimated, we recorded a difference in mean nest density for each model run, a 1 for a difference or a 0 for no difference. For the Bayesian model, we estimated the posterior distribution for the difference in nest densities between habitat types. We then calculated the cumulative probability of the lower tail of that distribution. We defined the tail as no difference between the means. We considered the densities different if this probability was 0.23 or less, which made the test for the Bayesian model equivalent to a $t$-test with $\alpha=0.05$. We fit a smoothing spline through our power calculations to smooth predictions because the Bayesian analysis was based on fewer simulated datasets. We then compared these results to those from the simulation using a $t$ test and observed nest-density estimates. We present individual means with standard errors (SE), comparative means with 95\% confidence intervals (CI), estimated means from models selected with AIC $c$ with $85 \% \mathrm{CI}$, and model-averaged coefficients $(\beta)$ with unconditional $85 \%$ confidence intervals (UCI) (Anderson 2008, Arnold 2010).

\section{RESULTS}

We searched for Western Meadowlark nests by rope dragging to estimate density in seven wet meadow pastures (mean size $57 \pm 5$ ha, range 38-70 ha) and four upland prairie pastures (61 \pm 10 ha, range 43-90 ha), representing a total area of 396 and 245 ha, respectively. We conducted 52 rope-drag trials on 23 nests $(2.3 \pm 0.2$ trials per nest, range $1-5)$, including 10 nests subjected to a single trial and 13 nests subjected to more than one trial. Time elapsed between trials at nests with
TABLE 1. Models for probability of adult Western Meadowlarks attending and flushing from nests in the Nebraska Sandhills, 2007. $K$, number of model parameters; $\ln L, \log$ likelihood; $\Delta \mathrm{AIC}_{c}$, relative differences in values of Akaike's information criterion for small sample sizes; $w_{i}$, weight.

\begin{tabular}{lcccc}
\hline \hline Model & $K$ & $\ln L$ & $\Delta \mathrm{AIC}_{c}$ & $w_{i}$ \\
\hline Attending nest & & & & \\
$\quad$ Vegetation density & 2 & -32.8 & 0.0 & 0.63 \\
$\quad$ Nest stage & 2 & -34.2 & 2.8 & 0.16 \\
$\quad$ Null & 1 & -35.9 & 4.1 & 0.08 \\
Global & 5 & -31.4 & 4.4 & 0.07 \\
$\quad$ Ordinal day & 2 & -35.8 & 6.0 & 0.03 \\
$\quad$ Time of day & 2 & -35.8 & 6.1 & 0.03 \\
Flushing from nest & & & & \\
$\quad$ Null & 1 & -25.5 & 0.0 & 0.30 \\
$\quad$ Nest stage & 2 & -24.5 & 0.2 & 0.27 \\
$\quad$ Vegetation density & 2 & -25.0 & 1.2 & 0.17 \\
Ordinal day & 2 & -25.1 & 1.5 & 0.14 \\
$\quad$ Time of day & 2 & -25.5 & 2.2 & 0.10 \\
$\quad$ Global & 5 & -23.3 & 4.8 & 0.03 \\
\hline
\end{tabular}

greater than one trial was $90 \pm 10 \mathrm{hr}$ (range $42-270 \mathrm{hr}$ ). Time of day for trials was 13:27 \pm 0.8 (range 07:50-19:33). Age of nests during trials was $14.9 \pm 1.2$ days (range 3-28 days) after clutch initiation, with 32 and 20 trials during the egg and nestling stages, respectively. Vegetation density at nests for trials during which adults were attending nests and absent from nests was $19.6 \mathrm{~cm}(95 \%$ CI $17.3-21.8)$ and $23.8 \mathrm{~cm}(95 \%$ CI 21.5-26.1), respectively. Vegetation density at nests for trials during which attending adults did and did not flush was $23.6 \mathrm{~cm}$ (95\% CI 21.3-25.9) and $16.7 \mathrm{~cm}$ (95\% CI 14.0-19.4), respectively.

Adults attended nests during 24 of 52 trials (46\%). The vegetation-density model for probability of adults attending nests was most informative within our model set, but modelselection uncertainty was high so we report model-averaged coefficients (Table 1). Vegetation density $(\beta=-0.120,85 \%$ $\mathrm{UCI}=-0.195$ to -0.046$)$ and nest stage $\left(\beta_{\text {nestling }}=-1.074,85 \%\right.$ $\mathrm{UCI}=-1.979$ to -0.168$)$ were negatively correlated with probability of nest attendance (Fig. 1), but UCI for time of day ( $\beta=$ $0.000,85 \%$ UCI $-0.002-0.001)$ and ordinal day $(\beta=0.004$, $85 \%$ UCI $-0.017-0.025)$ overlapped zero. The estimated probability of attendance from the null model was 0.46 (85\% CI $0.37-0.56$ ).

Adults flushed from nests during 10 of 52 trials (19\%). Model-selection uncertainty was high among models for probability of flushing (Table 1). Model-averaged coefficients for vegetation density $(\beta=0.065,85 \% \mathrm{UCI}-0.027-0.157)$, time of day ( $\beta=0.000,85 \%$ UCI $0.002-0.002)$, ordinal day $(\beta=-0.011,85 \%$ UCI $-0.032-0.010)$, and nest stage $\left(\beta_{\text {nestling }}=\right.$ $-1.124,85 \%$ UCI $-2.37-0.123)$ overlapped zero. The estimated probability of flushing (including when adults were confirmed 


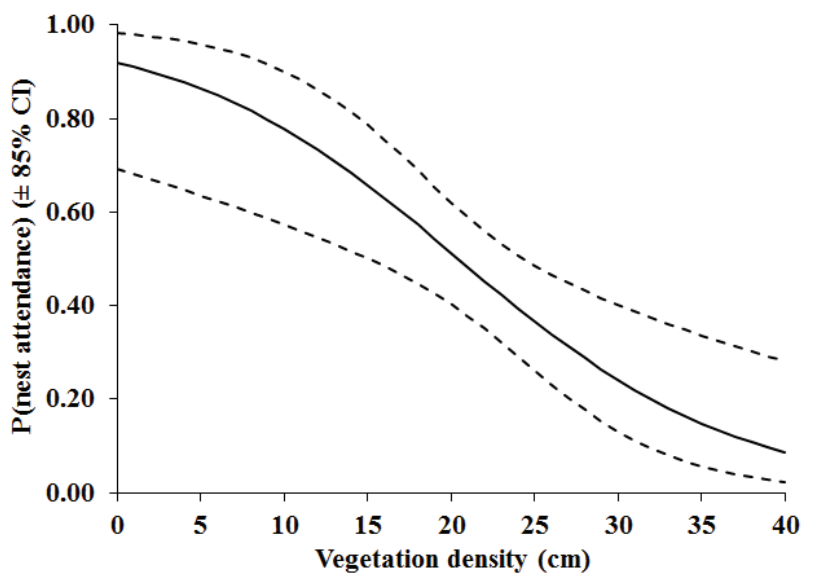

FIGURE 1. Model-predicted probabilities ( $\pm 85 \%$ confidence intervals) of nest attendance as a function of vegetation density around nests of Western Meadowlarks in the Nebraska Sandhills, 2007.

post-trial as absent) from the null model was 0.19 (85\% CI $0.13-0.28)$. Given adults' attendance at nests, adults flushed during 10 of 24 trials ( $42 \%$ ), and the probability of flushing from the null model was $0.42(95 \%$ CI $0.24-0.60)$. As researchers do not know if nests are attended by adults while searching for new nests by rope dragging, our detectability estimate of 0.19 is the most realistic in practice.

Given attendance by adults at nests, the probabilities of adults responding to trials when preceded and not preceded by previous trials were 0.44 (95\% CI $0.18-0.75$ ) and 0.40 (95\% CI 0.19-0.65), respectively, suggesting that the probability of adults flushing in response to subsequent trials was not affected by exposure to previous trials. Given attendance by adults at nests, the probabilities of adults flushing in response to trials at nests that survived from the egg to nestling stage $(n=13)$ and at nests that failed in the egg stage $(n=10)$ were 0.50 (95\% CI $0.22-0.78)$ and 0.38 (95\% CI 0.13-0.72), respectively. Probabilities of nest-attending adults flushing in response to trials at nests that fledged nestlings $(n=9)$ and at nests that failed $(n=14)$ were $0.43(95 \%$ CI $0.14-0.77)$ and $0.45(95 \%$ CI $0.20-0.73$ ), respectively, indicating that probabilities of adults flushing from more or less successful nests did not vary.

We observed greater densities of nests in wet meadows (1.7 nests per 10 ha, $95 \%$ CI $0.8-2.6$ ) than in upland prairie pastures ( 0.1 nests per 10 ha, $95 \%$ CI $0.0-0.3$ ) (Table 2). Predictions from the Bayesian hierarchical model of nest density for wet meadows and upland prairie pastures were $14.2 \pm 1.1$ nests per 10 ha and $1.5 \pm 0.3$ nests per 10 ha, respectively, an increase of $12 \%$ and $7 \%$ over apparent estimates of nest density. While differences between habitat types in apparent nest densities were clearly large, our power analysis illustrates that using uncorrected estimates of apparent nest density provided less power to detect differences between habitat types than that obtained from model-predicted estimates of nest density
TABLE 2. Observed and model-predicted estimates of mean nest density in lowland wet meadow (WM) and upland prairie (UP) pastures and estimation bias $(\Delta=$ predicted - observed) for Western Meadowlarks in the Nebraska Sandhills, 2007.

\begin{tabular}{|c|c|c|c|c|c|}
\hline \multirow[b]{2}{*}{ Pasture } & \multirow[b]{2}{*}{$\begin{array}{l}\text { Area } \\
\text { (ha) }\end{array}$} & \multirow[b]{2}{*}{ Nests } & \multicolumn{3}{|c|}{ Nest density (nests $10 \mathrm{ha}^{-1}$ ) } \\
\hline & & & Observed & $\begin{array}{l}\text { Predicted } \\
\quad( \pm \text { SE })\end{array}$ & $\Delta$ \\
\hline WM1 & 63.4 & 25 & 3.9 & $14.7 \pm 0.7$ & 10.7 \\
\hline WM2 & 61.7 & 15 & 2.4 & $13.4 \pm 0.7$ & 11.0 \\
\hline WM3 & 70.4 & 13 & 1.8 & $11.5 \pm 0.6$ & 9.7 \\
\hline WM4 & 37.8 & 6 & 1.6 & $19.6 \pm 1.2$ & 18.0 \\
\hline WM5 & 67.6 & 7 & 1.0 & $11.1 \pm 0.7$ & 10.1 \\
\hline WM6 & 49.0 & 3 & 0.6 & $14.5 \pm 0.9$ & 13.9 \\
\hline WM7 & 46.1 & 1 & 0.2 & $15.0 \pm 1.0$ & 14.8 \\
\hline UP1 & 43.1 & 2 & 0.5 & $2.3 \pm 0.5$ & 1.9 \\
\hline UP2 & 61.1 & 0 & $0.0^{\mathrm{a}}$ & $1.3 \pm 0.4^{\mathrm{a}}$ & 1.3 \\
\hline UP3 & 51.1 & 0 & $0.0^{\mathrm{a}}$ & $1.6 \pm 0.4^{\mathrm{a}}$ & 1.6 \\
\hline UP4 & 90.0 & 0 & $0.0^{\mathrm{a}}$ & $0.9 \pm 0.2^{\mathrm{a}}$ & 0.9 \\
\hline
\end{tabular}

${ }^{\mathrm{a}}$ No nests observed. Predictions based on apparent mean nest density of UP $1-4$.

corrected for detection error (Fig. 2). For example, we would need a difference in mean nest density of $>0.20$ nests $^{-1} a^{-1}$ to achieve statistical power of 0.80 with our first simulation model based on apparent nest densities. We achieved the same level of power with a mean difference of approximately 0.10 nest $\mathrm{ha}^{-1}$ by correcting for detection error in our hierarchical simulation model (Fig. 2).

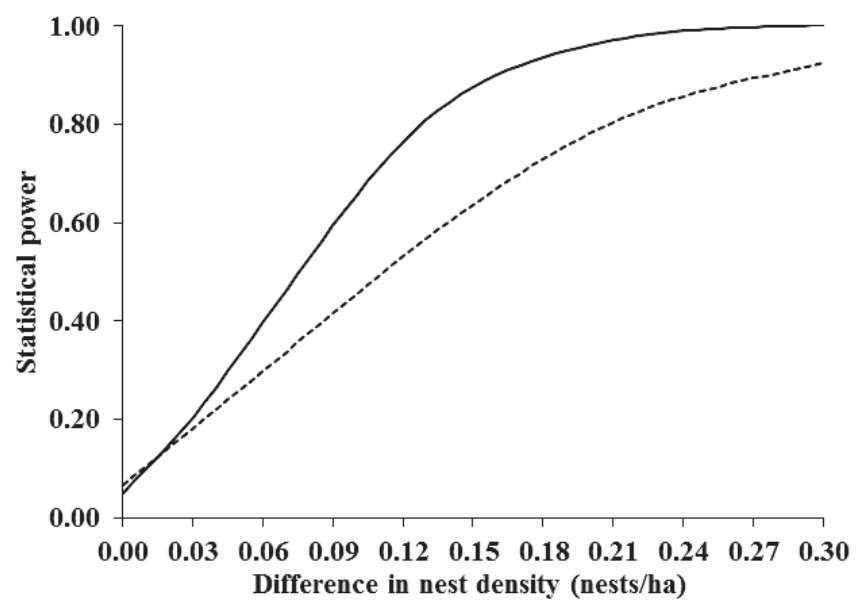

FIGURE 2. Simulation-based power analysis illustrating statistical power to detect a difference in mean nest densities between habitat types for the Western Meadowlark in the Nebraska Sandhills, 2007. Solid line, power of detecting a difference between habitat types with mean nest-density parameters corrected for detection error in a Bayesian hierarchical model. Dashed line, power of detecting a difference between habitat types with a one-tailed, independent $t$-test $(\alpha=0.05)$ of apparent, uncorrected mean densities of nests. 


\section{DISCUSSION}

Our results illustrate that finding nests by rope dragging or similar cue-based methods depends primarily on (1) adults attending nests and, (2) given the presence of adults, adults responding to disturbance produced by the rope, both of which are primary sources of variation in availability and neither of which were constant according to our data. Variation in rates of nest attendance and responses by adults produced a high level of detection error, a low probability of detecting nests, negatively biased estimates of nest density, and diminished statistical power for revealing differences in nest densities between habitat types. Our estimates of nest density are relative, but researchers could estimate more absolute densities by incorporating information from daily nest-survival data, thus accounting for nests that failed before detection (Mayfield 1961, Shaffer 2004).

We assumed that our ability to detect responses by adults during rope-drag trials was $100 \%$, but rope-drag surveys for undiscovered nests may also be subject to variation in the perceptibility component of detectability because of observer error in detecting flight responses and locating associated nests. Species-specific behavioral and/or morphological traits may affect the ability of observers to detect nests. For example, species of the order Galliformes may be more likely to flee nests on foot and under dense vegetation cover, thereby potentially avoiding detection. Observers may also fail to detect inconspicuous flight responses from physically less conspicuous species such as the Grasshopper Sparrow (Ammodramus savannarum). Numerous researchers have partially accounted for the perceptibility component of detection error by isolating inter-observer variation from estimates of nest density. For example, Nichols et al. (1986) applied an observer-based, capture-recapture approach to account for detection error during surveys for nests of the White-winged Dove (Zenaida asiatica), and Conway and Simon (2003) used a double-observer method to estimate detectability of nest sites of the Burrowing Owl (Athene cunicularia). Such methods partially address the perceptibility component of detection error by accounting for inter-observer variation, but they do not directly address the availability component by identifying and quantifying the underlying mechanisms.

Detection error inherent to the rope-drag method could be decreased by increasing the number of observers and spacing them more closely as they search (Renfrew et al. 2005). Increased sampling intensity could thus decrease bias by increasing probabilities of nest-attending adults responding to disturbance, but it still may not reveal all nests present if nests are not attended by adults and available for detection. Increasing the frequency of searches by sampling sites repeatedly until no additional nests are located may also increase the probability of finding adults attending nests (McLandress et al. 1996, Ackerman et al. 2004). Similarly, repeated visits can be used to increase probabilities of detecting nests, but the number of visits required to maximize nest detectability can vary by species, and repeated visits are effective only for species with periods of nest survival long enough to accommodate multiple visits (Smith et al. 2009).

Other researchers have used alternative methods for finding nests, such as walking 1-m-wide transects with or without tools to part vegetation (Basore et al. 1986, Bryan and Best 1994, Camp and Best 1994, Scheiman et al. 2003, Henningson and Best 2005, Smythe and Haukos 2009), focused observation of adults' behavior (Martin and Guepel 1993, Winter et al. 2003), or tracking females to nests with radiotelemetry (Powell et al. 2005). These approaches may reduce detection bias in searches for nests, but we contend that most of them are also subject to detection error and consequent bias in estimates of nest density. The extent of detection error and bias, however, will vary depending primarily on (1) the type of method and sampling intensity, (2) species-, nest-stage-, and time-specific rates of nest attendance and behavioral response, and (3) nest-site structure and weather conditions. For example, observers spaced closer together and walking transects while parting vegetation may be more effective than the rope-drag method in eliciting flight responses by adults. Such methods, however, cover less area than the rope dragging with equivalent time invested, and they are still conditional on adults attending nests.

Numerous factors should be accounted for in sampling and modeling designs used to estimate nest detectability and density for grassland birds. Our sample of rope-drag trials was too small to reveal correlations between ordinal day and time of day with probabilities of nest attendance and flushing by adults. In reality, however, variation in nest attendance within a day and among days (i.e., season effects) could affect estimates of nest detectability and density (Gloutney et al. 1993; Davis and Donald, in press).

Density of vegetation at nest sites may be an important factor for sampling and modeling nest detectability. Renfrew et al. (2005) suggested the rope-drag method is less effective as plant height increases through the growing season, and Burhans and Thompson (2001) found nest concealment and distance to approaching observer before adults responded to be inversely related. Our data provide further evidence that behavior of nest-attending adults can vary with level of nest concealment. For grassland passerines, this relationship could be magnified if birds perceive a dragged rope as a source of disturbance less intense than direct approach by researchers (as in Burhans and Thompson 2001). We recommend that researchers use sampling and modeling designs accounting for study-specific variables that produce detection error, including variables representing time (e.g., time of day, time of season, and nest age or stage), nest-site structure, and interobserver effects (i.e., perceptibility) related to detection of adults flushing from nests. 
Our model and predictions could be refined by allowing the probability of nest detection to vary stochastically, but our primary goal was to demonstrate that incorporating sources of detection error can help researchers make more accurate ecological inference. Researchers modeling nest density for grassland birds may benefit from a sampling design similar to ours, in which rope-drag trials (or equivalent method) are conducted on subsamples of known nests to quantify and correct for detection error. Subsequent estimation of nest density with a hierarchical modeling approach (e.g., Royle 2004) should produce more accurate estimates of nest density and associated effects of ecological variables.

\section{ACKNOWLEDGMENTS}

Funding was provided by the University of Nebraska-Lincoln (UNL) Foundation's Burlington Northern Water Science Endowment, Department of Agronomy and Horticulture, School of Natural Resources, and Undergraduate Creative Activities and Research Experience Program. We are grateful for additional support from the UNL Center for Great Plains Studies' Graduate Student Grant, the UNL Center for Grassland Studies' A. W. Sampson Graduate Fellowship in Range Science, and the Nebraska chapter of The Nature Conservancy's J. E. Weaver Competitive Grant. This research was supported by Hatch Act funds through the University of Nebraska Agricultural Research Division, Lincoln, Nebraska. We thank L. Thacker-Lynn and J. Warner for dedicated sampling effort and the staff at the UNL Gudmundsen Sandhills Laboratory for logistical support. We thank C. Ribic for an early review, and three reviewers, M. Patten, and P. Unitt for vastly improving our manuscript.

\section{LITERATURE CITED}

Ackerman, J. T., A. L. Blackmer, AND J. M. EAdie. 2004. Is predation on waterfowl nests density dependent? Oikos 107:128-140.

Alldredge, M. W., T. R. Simons, And K. H. Pollock. 2007. Factors affecting aural detections of songbirds. Ecological Applications 17:948-955.

Anderson, D. R. 2008. Model based inference in the life sciences. Springer Science, New York.

Arnold, T. W., L. M. Craig-Moore, L. M. Armstrong, D. W. Howerter, J. H. DeVries, B. L. Joynt, R. B. Emery, and M. G. Anderson. 2007. Waterfowl use of dense nesting cover in the Canadian Parklands. Journal of Wildlife Management 71:25422549.

Basore, N. S., L. B. Best, And J. B. Wooley JR. 1986. Bird nesting in Iowa no-tilled and tillage cropland. Journal of Wildlife Management 50:19-28.

BennetT, L. J. 1938. The Blue-winged Teal: its ecology and management. Collegiate Press, Ames, IA.

Best, L. B. 1981. Seasonal changes in detection of individual bird species. Studies in Avian Biology 6:252-261.

Bolker, B. M. 2008. Ecological models and data in R. Princeton University Press, Princeton, NJ.

Bowen, B. S., AND A. D. KRUSE. 1993. Effects of grazing on nesting of Upland Sandpipers in south-central North Dakota. Journal of Wildlife Management 57:291-301.

Bryan, G. G., AND L. B. BEST. 1994. Avian nest density and success in grassed waterways in Iowa row crop fields. Wildlife Society Bulletin 22:583-592.
Burhans, D. E., AND F. R. THOMPSON III. 2001. Relationship of songbird nest concealment to nest fate and flushing behavior of adults. Auk 118:237-242.

CAMP, M., AND L. B. BEST. 1994. Nest density and nesting success of birds in roadsides adjacent to row crop fields. American Midland Naturalist 131:347-358.

Conway, C. J., AND J. C. SimON. 2003. Comparison of detection probability associated with Burrowing Owl survey methods. Journal of Wildlife Management 67:501-511.

CoWAN, W. F. 1982. Waterfowl production on zero-tillage farms. Wildlife Society Bulletin 10:305-308.

DAVIS, S. K., AND T. G. DonalD. In press. Sprague's Pipit incubation behavior reveals optimal times to locate and monitor nests. Studies in Avian Biology.

Davis, S. K., AND W. E. LANYON [ONLINE]. 2008. Western Meadowlark (Sturnella neglecta), no. 104. In A. Poole [ED.], The Birds of North America online. Cornell Lab of Ornithology, Ithaca, NY. $<$ http://bna.birds.cornell.edu.bnaproxy.birds.cornell.edu/bna/ species/104doi:10.2173/bna.104> (1 October 2010).

Devries, J. H., AND L. M. ARMSTRONG. In press. Impact of management treatments on waterfowl use of dense nesting cover in the Canadian Parklands. Journal of Wildlife Management.

Diefenbach, D. R., D. W. Brauning, and J. A. Mattice. 2003. Variability in grassland bird counts related to observer differences and species detection rates. Auk 120:1168-1179.

DuebBert, H. F., AND H. A. Kantrud. 1987. Use of no-till winter wheat by nesting ducks in North Dakota. Journal of Soil and Water Conservation 42:50-53.

EARL, J. P. 1950. Production of Mallards on irrigated land in the Sacramento Valley, California. Journal of Wildlife Management $14: 332-342$

Fondell, T. F., AND I. J. BALl. 2004. Density and success of bird nests relative to grazing on western Montana grasslands. Biological Conservation 117:203-213.

FRAWLEY, B. J., AND L. B. BEST. 1991. Effects of mowing on breeding bird abundance and species composition in alfalfa fields. Wildlife Society Bulletin 19:135-142.

Frey, C. M., W. E. Jensen, AND K. A. With. 2008. Topographic patterns of nest placement and habitat quality for grassland birds in tall-grass prairie. American Midland Naturalist 160:220-234.

George, T. L., A. C. Fowler, R. L. Knight, and L. C. McEwen. 1992. Impacts of a severe drought on grassland birds in western North Dakota. Ecological Applications 2:275-284.

Ghalambor, C. K., AND T. E. Martin. 2001. Fecundity-survival trade-offs and parental risk-taking in birds. Science 292:494-497.

Gilks, W. R., S. Richardson, and D. J. Spiegelhalter. 1995. Markov chain Monte Carlo in practice. Chapman and Hall, London.

GiovanNi, M. D. 2009. Demographics and microhabitat selection for the Western Meadowlark (Sturnella neglecta) in the Nebraska Sandhills. Ph.D. dissertation, University of Nebraska-Lincoln, Lincoln, NE.

Gloutney, M. L., R. G. Clark, A. D. Afton, and G. J. Huff. 1993. Timing of nest searches for upland nesting waterfowl. Journal of Wildlife Management 57:597-601.

Grier, J. W., J. M. Gerrard, G. D. Hamilton, And P. A. Gray. 1981. Aerial-visibility bias and survey techniques for nesting Bald Eagles in northern western Ontario. Journal of Wildlife Management 45:83-92.

Henningson, J. C., AND L. B. Best. 2005. Grassland bird use of riparian filter strips in southeast Iowa. Journal of Wildlife Management 69:198-210.

Higgins, K. F., L. M. Kirsch, AND I. J. BALl JR. 1969. A cable-chain device for locating duck nests. Journal of Wildlife Management 33:1009-1011. 
JOHNSON, D. H. 2008. In defense of indices: the case of bird surveys. Journal of Wildlife Management 72:857-868.

Kershner, E. L., AND E. K. Bollinger. 1996. Reproductive success of grassland birds at east-central Illinois airports. American Midland Naturalist 136:358-366.

Kruse, A. D., AND B. S. BowEN. 1996. Effects of grazing and burning on densities and habitats of breeding ducks in North Dakota. Journal of Wildlife Management 60:233-246.

LABISKY, R. F. 1957. Relation of hay-harvesting to duck nesting under a refuge-permittee system. Journal of Wildlife Management 21:194-200.

Lokemoen, J. T., And J. A. Beiser. 1997. Bird use and nesting in conventional, minimum tillage, and organic cropland. Journal of Wildlife Management 61:644-655.

Lunn, D. J., A. Thomas, N. Best, And D. Spiegelhalter. 2000. WinBUGS - a Bayesian modeling framework: concepts, structure, and extensibility. Statistics and Computing 10:325-337.

Luscier, J. D., AND W. L. THOMPSON. 2009. Short-term responses of breeding birds of grassland and early successional habitat to timing of haying in northwestern Arkansas. Condor 111:538-544.

Mackenzie, D. I., J. D. Nichols, G. B. Lachman, S. Droege, J. A. Royle, and C. A. Langtimm. 2002. Estimating site occupancy rates when detection probabilities are less than one. Ecology $83: 2248-2255$.

Martin, T. E., AND G. R. GeuPel. 1993. Nest-monitoring plots: methods for locating nests and monitoring success. Journal of Field Ornithology 64:507-519.

MAYFIELD, H. 1961. Nesting success calculated from exposure. Wilson Bulletin 73:255-261.

Mazerolle, M. J. 2010. AICcmodavg: model selection and multimodel inference based on (Q)AIC(c). R package version 1.13 . $<$ http://cran.r-project.org/web/packages/AICcmodavg/index.html> (16 January 2011).

McCarthy, M. A. 2007. Bayesian methods for ecology. Cambridge University Press, New York.

Mclandress, M. R., G. S. Yarris, A. E. H. Perkins, D. P. ConNELLY, AND D. G. RAVELING. 1996. Nesting biology of Mallards in California. Journal of Wildlife Management 60:94-107.

McMaster, D. G., J. H. Devries, And S. K. Davis. 2005. Grassland birds nesting in hay lands of southern Saskatchewan: landscape influences and conservation priorities. Journal of Wildlife Management 69:211-221.

MCSHEA, W. J., AND J. H. RAPPOLE. 1997. Variable song rates in three species of passerines and implications for estimating bird populations. Journal of Field Ornithology 68:367-375.

Nichols, J. D., R. E. Tomlinson, AND G. Waggerman. 1986. Estimating nest detection probabilities for White-winged Dove nest transects in Tamaulipas, Mexico. Auk 103:825-828.

O'Leary, C. H., AND D. W. NyBerg. 2000. Treelines between fields reduce the density of grassland birds. Natural Areas Journal 20:243-249.

Powell, L. A., M. J. Conroy, D. G. Krementz, and J. D. Lang. 1999. A model to predict breeding-season productivity for multibrooded songbirds. Auk 116: 1001-1008.
Powell, L. A., M. D. Giovanni, S. Groepper, M. L. Reineke, And W. H. Schacht. In press. Attendance patterns, predators, and survival of Western Meadowlark nests under video observation in the Nebraska Sandhills. Studies in Avian Biology.

Powell, L. A., J. D. Lang, D. G. Krementz, and M. J. Conroy. 2005. Use of radio-telemetry to reduce bias in nest searching. Journal of Field Ornithology 76:274-278.

R Development Core Team [OnLine]. 2007. R version 2.6.0: a language and environment for statistical computing. R Foundation for Statistical Computing, Vienna, Austria. <http://www.R-project. org $>$ (1 October 2010).

RalPH, C. J. 1981. An investigation of the effect of seasonal activity levels on avian censusing. Studies in Avian Biology 6:265270.

Renfrew, R. B., C. A. Ribic, And J. L. NACK. 2005. Edge avoidance by nesting grassland birds: a futile strategy in a fragmented landscape. Auk 122:618-636.

RICKLEFS, R. E. 1977. Reactions of some Panamanian birds to human intrusion at the nest. Condor 79:376-379.

Robel, R. J., J. N. Briggs, A. D. Dayton, And L. C. Hulbert. 1970. Relationships between visual obstruction measurements and weight of grassland vegetation. Journal of Range Management 23:295-297.

Robert, C. P., AND G. CASElla. 1999. Monte Carlo statistical methods. Springer-Verlag, New York.

RoYLE, J. A. 2004. $N$-mixture models for estimating population size from spatially replicated counts. Biometrics 60:108-115.

Scheiman, D. M., E. K. Bollinger, and D. H. Johnson. 2003. Effects of leafy spurge infestation on grassland birds. Journal of Wildlife Management 67:115-121.

SHAFFER, T. L. 2004. A unified approach to analyzing nest success. Auk 121:526-540.

Simons, T. R., M. W. Alldredge, K. H. Pollock, And J. M. WetTROTH. 2007. Experimental analysis of the auditory detection process on avian point counts. Auk 124:986-999.

SMith, P. A., J. BARt, R. B. LANCtot, B. J. McCAfFery, AND S. Brown. 2009. Probability of detection of nests and implications for survey design. Condor 111:414-423.

Smythe, L. A., AND D. A. Haukos. 2009. Nesting success of grassland birds in shinnery oak communities treated with Tebuthiuron and grazing in eastern New Mexico. Southwestern Naturalist 54:136-145.

Tyre, A. J., B. Tenhumberg, S. A. Field, D. Niejalke, K. Parris, AND H. P. Possingham. 2003. Improving precision and reducing bias in biological surveys: estimating false-negative error rates. Ecological Applications 13:1790-1801.

Winter, M., S. E. Hawks, J. A. Shaffer, And D. H. Johnson. 2003. Guidelines for finding nests of passerine birds in tall-grass prairie. Prairie Naturalist 35:196-211.

Ydenberg, R. C., AND L. M. Dill. 1986. The economics of fleeing from predators. Advances in the Study of Behavior 16:229249. 